\title{
Genetic Study of a New X-linked Recessive Immunodeficiency Syndrome
}

\author{
G. de Saint-Basile, F. Le Deist, M. Caniglia, Y. Lebranchu, C. Griscelli, and A. Fischer \\ Institut National de la Santé et de la Recherche Médicale (INSERM), U 132, Hôpital des Enfants-Malades, \\ 75743 Paris Cedex 15, France; and Unité de Pédiatrie, Centre Hospitalier Régional Tours, 37044 Tours, France
}

\begin{abstract}
Seven forms of X-linked (XL) immunodeficiency have been described (XL agammaglobulinemia, XL severe combined immunodeficiency [SCID], Wiskott-Aldrich syndrome, XL chronic granulomatous disease, XL hyper-IgM syndrome with low IgG and IgA, and XL lymphoproliferative syndrome), and properdine deficiency. Although there are (some) phenotypic variants, diagnosis is relatively simple on the basis of clinical, immunological, and genetic characteristics. We studied a family in which several males were affected by severe infections and whose pedigree suggested recessive $X L$ inheritance of an immunodeficiency. Immunologic and genetic studies ( $X$ inactivation patterns in females and restriction fragment length polymorphism [RFLP] segregation) were performed in order to characterize the immunodeficiency. The propositus, a 5-yr-old boy, was found to have a severe and progressive $T$ - and B-cell functional immunodeficiency characterized by defective antigenspecific responses. No lymphocyte subsets or membrane anomalies were detected and the immunodeficiency did not correspond to usual XL forms. Studies of DNA from two of the informative females, the mother and one sister revealed nonrandom $X$ chromosome inactivation of $T$ cells and, partially, $B$ cells but not $P M N$, a pattern similar to that observed in XL SCID carriers. RFLP studies identified a haplotype segregating with the abnormal locus that may be localized in the proximal part of the long arm of the $\mathrm{X}$ chromosome. We thus report the characterization of a new XL immunodeficiency that may correspond either to another XL locus or to an attenuated phenotype of XL SCID. (J. Clin. Invest. 1992. 89:861-866.) Key words: restriction fragment length polymorphism - T-cell function $\bullet \mathbf{X}$ inactivation study $\bullet \mathbf{X}$-linked immunodeficiency
\end{abstract}

\section{Introduction}

Six X-linked (XL) ${ }^{1}$ immunodeficiencies (ID) have so far been characterized. In XL chronic granulomatous disease (CGD),

Address reprint requests to Dr. de Saint-Basile, INSERM U132, Hôpital des Enfants-Malades, 149 rue de Sèvres, 75743 Paris Cédex 15, France.

Received for publication 8 April 1991 and in revised form 17 September 1991.

1. Abbreviations used in this paper: $\mathrm{CGD}$, chronic granulomatous disease; $\mathrm{E}^{+}, \mathrm{E}$ rosette positive; ID, immunodeficiency; MLR, mixed leukocyte reaction; NBT, nitroblue tetrazolium; RFLP, restriction fragment length polymorphism; SCID, severe combined immunodeficiency, WAS, Wiskott-Aldrich syndrome; XL, X-linked; XLA, $\mathrm{X}$-linked agammaglobulinemia.

J. Clin. Invest.

(c) The American Society for Clinical Investigation, Inc.

$0021-9738 / 92 / 03 / 0861 / 06 \$ 2.00$

Volume 89, March 1992, 861-866 granulocytes and monocytes are unable to kill microorganisms because of a cytochrome $\beta$ chain defect $(1,2)$. XL agammaglobulinemia (XLA) is due to an early arrest in B-cell maturation; the abnormal (unknown) gene is localized in Xq21.3-22 (3). XL severe combined immunodeficiency (SCID) is characterized by an absence of $\mathrm{T}$ lymphocytes, the abnormal locus being mapped in Xq13 (4). Hyper-IgM syndrome with low IgG and IgA is an Ig switch defect, the locus of which has been mapped to Xq24-27 (5). XL lymphoproliferative syndrome is characterized by an abnormal susceptibility to Epstein-Barr virus (EBV) infection, the gene being localized in Xq25 (6). Finally, Wiskott-Aldrich syndrome (WAS) is associated with platelet anomalies and has been mapped around Xp1 1.2 $(7,8)$. In this study, we report clinical, immunological, and genetic findings pertaining to a family in which several males have been affected by a T- and B-cell functional ID that does not correspond to any known XL form. This syndrome may represent either a new XL ID or an attenuated phenotype of XL SCID.

\section{Methods}

Immunologic investigations. Peripheral blood mononuclear cells (PBMC) and polymorphonuclear cells (PMN) were isolated from freshly drawn heparinized blood by means of Ficoll Hypaque (Pharmacia Fine Chemicals, Uppsala, Sweden) density centrifugation.

Fluorescence staining was performed on PBMC. The following monoclonal antibodies (MAbs) were used: anti-CD3, Leu4 (IgG2a) (Becton, Dickinson \& Co., Mountain View, CA); anti-T-cell receptor $\beta$, BMAO31 (IgG1) (Behring Werke, Marburg/Lahn, FRG); anti-Tcell receptor $\delta$, TCR $\delta 1$ (IgG1) (T-cell Sciences, Cambridge, MA); anti-CD2, Leu5b (IgG2a) (Becton, Dickinson \& Co.); anti-CD4, Leu3a (IgG1) (Becton, Dickinson \& Co.); anti-CD8, Leu2a (IgG1) (Becton, Dickinson \& Co.); anti-CD16; Leu 1 lb (IgG1) (Becton, Dickinson \& Co.); anti-CD45RO; UCHL-1 (IgG2a) (kindly provided by P. Beverley, ICRF, London); anti-CD45RA; 2H4 (IgG1) (Coulter Clone, Margency, France); anti-CD29; 4B4 (IgG1) (Coulter Clone); antimembrane IgM (Nordic, Tilburg, The Netherlands); anti-HLA class I; IOT2 (IgG2a) (Immunotech, Marseille, France); and anti-HLA class II DR; (IgG2a) (Becton, Dickinson \& Co.). Direct fluorescence staining was performed using phycoerythrin- or fluorescein (FITC)-conjugated monoclonal antibodies. A FITC-conjugated goat anti-mouse Ig (Nordic) was used for indirect immunofluorescence. The analysis was performed using a FACS STAR plus (Becton, Dickinson \& Co.).

Proliferation assays were performed as described elsewhere (9), using either mitogens in 4-d cultures or antigen and allogeneic cells in 6-d cultures. OKT3 antibody $(50 \mathrm{ng} / \mathrm{ml}$ ) (Ortho Diagnostic Systems, Inc., Raritan, NJ); anti-CD2 antibody pairs, D66 + T11.1 antibody (10) (final dilution 1/200) kindly provided by A. Bernard, CHRU, Nice, France; and phytohemagglutinin (PHA) (Difco, Inc., Detroit, MI) (final dilution 1/700) were used as mitogens. Specific T-cell proliferation was driven by tetanus toxoid (Pasteur Institut, Marne la Coquette, France; final dilution 1/250). Candidin (Pasteur Institut; $10 \mu \mathrm{g} / \mathrm{ml}$ ), or allogeneic cells.

DNA analysis. Total genomic DNA was extracted from E-rosettepositive $\left(\mathrm{E}^{+}\right)$peripheral blood cells, PMN or Epstein-Barr virus-induced B cell lines $(11,12)$. The B cell lines were obtained by pooling three to five low-passage ( $1 \mathrm{mo}$ ) B-lymphoblastoid cultures. DNA puri- 
fication and hybridization with radiolabeled probes were performed as previously described (13). T-cell receptor rearrangement was performed using the cDNA T $\beta$ constant region (14) and the $J \gamma_{1}$ probe (pH60) (15) on EcoRI HindIII-and KpnI-digested $\mathrm{E}^{+}$-extracted DNA. Restriction fragment length polymorphism (RFLP) analysis was performed on Pst 1- or Taq1-digested DNA with appropriate polymorphic $\mathrm{X}$ chromosome markers. $\mathrm{X}$ chromosome inactivation studies were performed as previously described (16). Briefly, $20 \mu \mathrm{g}$ of DNA was digested with PstI and BstXI and divided into two 10- $\mu \mathrm{g}$ aliquots, one of which was further digested with $10 \mathrm{U}$ of HpaII. Southern blotting was then performed with the phosphoglycerate kinase pSPT19.1 polymorphic probe (17) and the hypervariable marker DXS255 (18).

Case report. The patient (III6 in Fig. 1) was the $5 \frac{1}{2}$-yr-old son of healthy Portugese parents. Because of the family history and preliminary results of immunologic investigations (see below), he received oral nonabsorbable antibiotics from day 15 of life onward, together with trimethoprim-sulfamethazole and ketoconazole. He remained healthy until the age of $9 \mathrm{mo}$, when he developed progressively protracted diarrhea with failure to thrive (growth $-1.5 \mathrm{SD}$ and weight $-2.5 \mathrm{SD}$ at the age of $16 \mathrm{mo}$ ). The serum concentration of the immunoglobulins were normal or elevated (Table I). Small-bowel and colon biopsies performed at the age of $5 \mathrm{yr}$ (June 1990) revealed partial villous atrophy and nonspecific colites. Lamina propria was infiltrated by mononuclear cells and also in colon by PMN. Microbiological findings were normal. He has recently been placed on parenteral nutrition. Despite continuous antibiotic therapy, he presented otitis media on several occasions. Tests performed regularly from birth revealed no hematologic anomalies a part from transient T-cell lymphocytopenia during the first 4 mo of life. Adenosine deaminase and purine nucleoside phosphorylase erythrocyte enzyme activities were normal. The nitroblue tetrazolium test (NBT) was normal, as was complement activity (CH50). HLA typing and karyotyping showed no evidence of maternal T-cell engraftment. The patient's serum was negative for HIV-1 and -2 antigens and antibodies.

Among his five siblings, the three sisters are healthy, although his two brothers (III2 and III3, Fig. 1) died of sepsis at the ages of $2 \frac{1}{2}$ yr and $5 \mathrm{mo}$, respectively. Both suffered intractable diarrhea of early onset (1st mo of life). The first child (III2) had multiple infections, including recurrent otitis media with mastoiditis and sepsis. A severe colitis required colectomy at the age of $2 \mathrm{yr}$ which was unsuccessful in controlling the diarrhea. At the age of $2 \frac{1}{2} \mathrm{yr}$, this child had 3,500 lymphocytes/ $\mu \mathrm{l}$ with $50 \%$ of E-rosette-forming cells, and a low $(3,400 \mathrm{cpm})$ response in the mixed leukocyte reaction (MLR). Serum IgG, IgA, and IgM levels were elevated. Postmortem examination revealed extreme thymic atrophy with rare Hassal's corpuscules, and there was a marked diffuse hypoplasia of the lymph nodes and spleen. The second child (III3) had 6,400 lymphocytes/ $\mu$ l with $28 \%$ of E-rosette-forming cells at the age of 2 mo.

In addition, a maternal uncle (II8) had died at the age of $5 \mathrm{yr}$ after repeated bouts of bronchopneumonitis with bronchiectasia, skin infections, protracted diarrhea, and failure to thrive. Postmortem examination revealed similar findings to those in case III2. Two of his brothers (II3 and 4) had died at the ages of 8 and 10 mo with severe diarrhea.

\section{Results}

Immunological investigations. As shown in Table II, except for the first $4 \mathrm{mo}$ of life, the patient had normal numbers of $\mathrm{T}$ and B lymphocytes and natural killer cells. The distribution of cell subsets was unremarkable. HLA class I and class II antigens were normally expressed. In contrast, T-cell function progressively declined (Fig. 2): antigen-induced T-cell proliferation to tetanus toxoid and Candida antigens, normal during the 1st yr of life, became negative despite two immunization shots with tetanus toxoid (Fig. 2). Similarly, MLR activity was very low (Table II) and cytotoxic T-cell responses were absent (not shown), whereas mitogen-induced T-cell responses were present (Table II). In vivo delayed-type skin hypersensitivity to

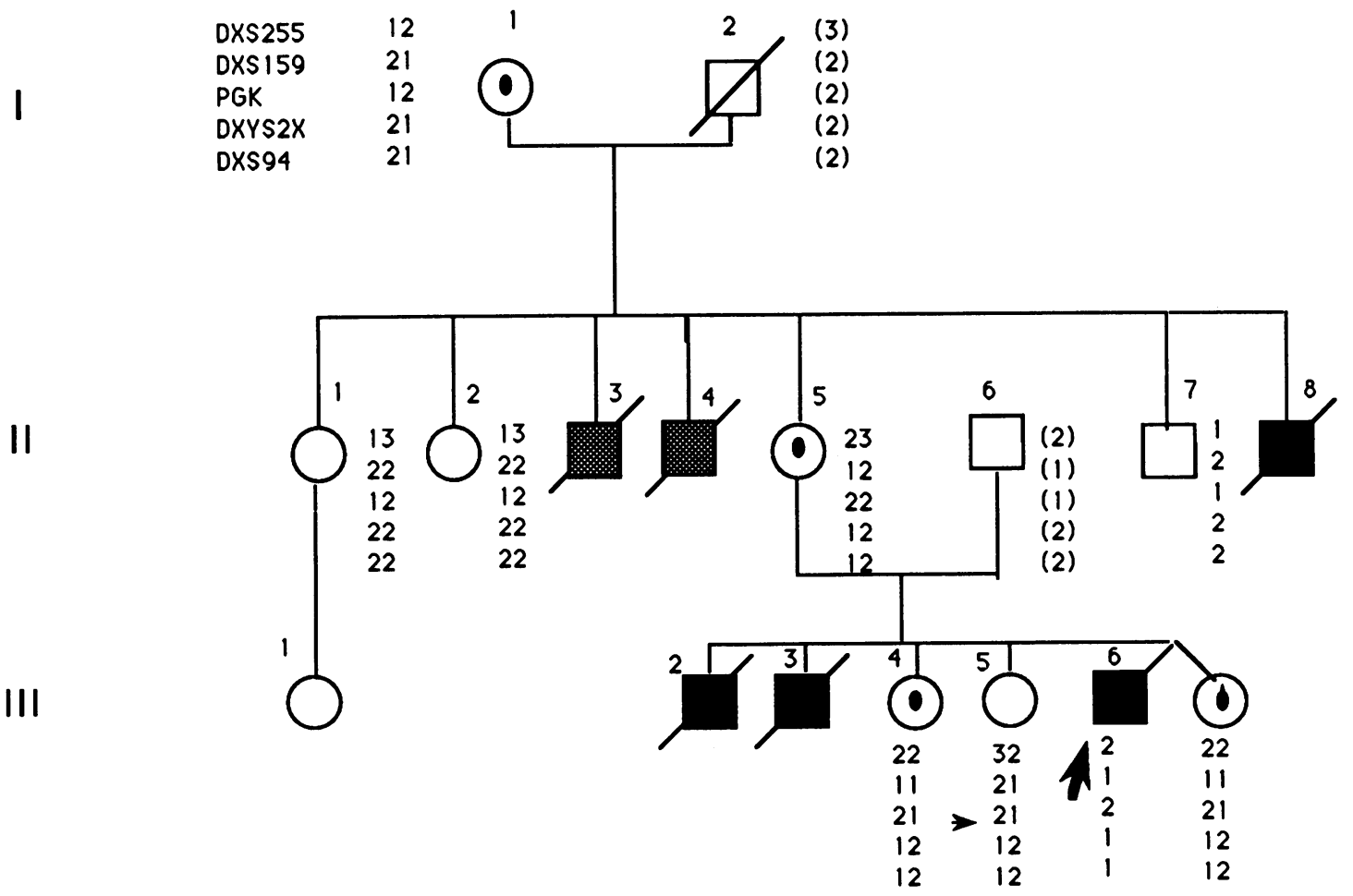

Figure 1. Family pedigree and segregation of the X chromosomal polymorphic loci: DXS255, DXS159, PGK, DXYS2X, and DXS94. (๓) Male with immunodeficiency; ( $\varpi$ ) male with suspected immunodeficiency. 
Table I. Serum Immunoglobulin Levels of the Propositus (III6) at Various Times before Immunoglobulin Substitution

\begin{tabular}{lcccr}
\hline & IgG & IgA & IgM & IgE \\
\hline & & g/liter & & IU/ml \\
Newborn & 12.2 & 0.14 & 0.25 & 10 \\
Age-matched control & $8.5 / 13.5$ & $0 / 0.5$ & $0.06 / 0.16$ & $\leq 10$ \\
4 mo & 3.08 & 0.33 & 0 & 40 \\
Age-matched control & $2.8 / 6.8$ & $0.1 / 0.58$ & $0.4 / 0.84$ & $\leq 10$ \\
1 yr & 5.64 & 1.20 & 0.95 & 580 \\
2 yr & 8.73 & 1.85 & 1.03 & 640 \\
Age-matched control & $5.3 / 10.1$ & $0.34 / 0.78$ & $0.54 / 1.06$ & $\leq 10$ \\
& & & & \\
\hline
\end{tabular}

Candida antigens was absent at 18 mo. Antibody responses that were first present to poliovirus and tetanus toxoid progressively disappeared (Fig. 3). A slight anmnestic response to tetanus toxoid was evoked after an immunization shot (Fig. 3). In addition, antibodies to Bordetella pertussis and diphtheria tox-

Table II. Immunological Analysis of the Patient's Peripheral Blood Leukocytes

\begin{tabular}{lcc}
\hline & \multicolumn{2}{c}{ Cellular immunity } \\
\cline { 2 - 3 } & Patient & Normal values \\
\hline $\begin{array}{c}\text { T lymphocytes, } \\
\left(C D 3^{+}\right) / \mu l\end{array}$ & $\begin{array}{c}300-600^{*} \\
1,500-2,000^{\ddagger} \\
170-750\end{array}$ & $1,200-2,500$ \\
$\begin{array}{c}\text { B lymphocytes, } \\
(\text { Sig }) / \mu l\end{array}$ & $320-380$ & $100-600$ \\
$\begin{array}{c}\text { Natural killer cells, } \\
(C D 56) / \mu l\end{array}$ & $100-500$ \\
\hline
\end{tabular}

Phenotype on T lymphocyte $\left(\mathrm{CD}^{+}\right)^{5}$

\begin{tabular}{|c|c|c|}
\hline $\mathrm{CD} 2$ & 99 & $90-100$ \\
\hline CD4 & $63 \pm 9$ & $60-80$ \\
\hline CD8 & $44 \pm 15$ & $20-40$ \\
\hline $\operatorname{TCR} \alpha \beta$ & 99 & $90-100$ \\
\hline $\operatorname{TRCR} \gamma \delta$ & 0 & $0-10$ \\
\hline CD45RO & 70 & $45-80$ \\
\hline CD45RA & 16 & $20-55$ \\
\hline CD29 & 82 & $45-80$ \\
\hline \multicolumn{3}{|c|}{$\mathrm{T}$ cell proliferation } \\
\hline & \multicolumn{2}{|c|}{$c p m \times 10^{-3}$} \\
\hline None day 4 & $0.8 \pm 0.4$ & $0.8 \pm 0.3$ \\
\hline PHA & $39.0 \pm 24.0$ & $126.0 \pm 37.0$ \\
\hline OKT3 & $28.6 \pm 17.7$ & $36.0 \pm 23.0$ \\
\hline $\begin{array}{l}\text { Anti-CD2 pair } \\
\quad(\text { D66-1 + T11-1) }\end{array}$ & $41.0 \pm 1.0$ & $110.0 \pm 55.0$ \\
\hline None day 6 & $0.7 \pm 0.4$ & $1.2 \pm 0.6$ \\
\hline Allogeneic cells & $3.3 \pm 3.6$ & $35.0 \pm 17.4$ \\
\hline
\end{tabular}

* Below the age of 4 mo.

₹ Above the age of $4 \mathrm{mo}$.

${ }^{8}$ Phenotyping performed when T lympocyte count was $2,500 / \mu 1$.

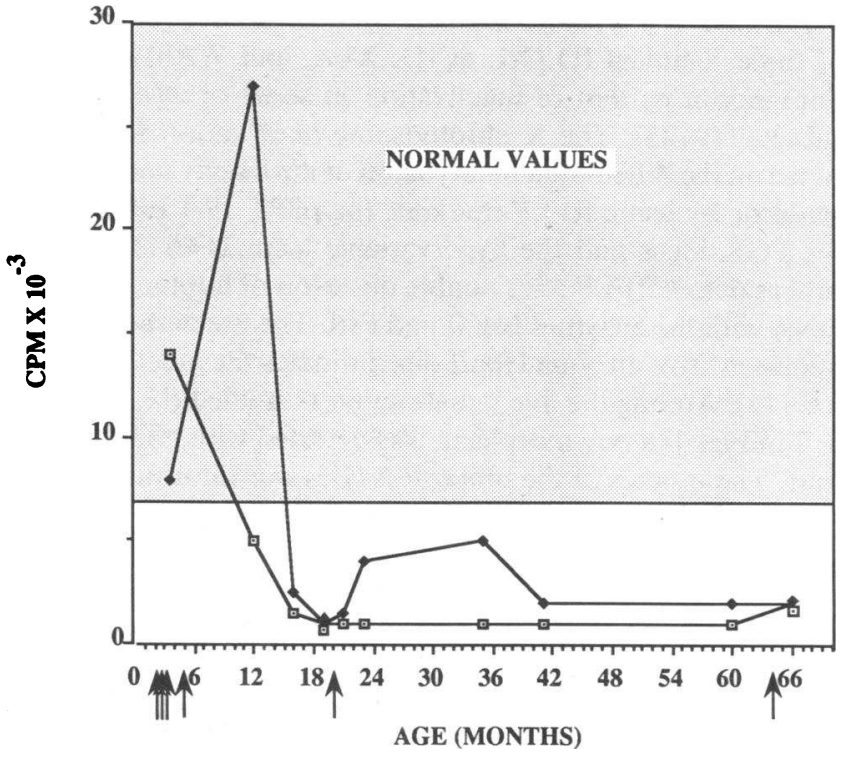

Figure 2. Time course of antigen-induced T cell proliferation. Arrows represent tetanus toxoid immunization shots. (অ) Proliferation to tetanus toxoid; ( $\bullet$ ) proliferation to Candida antigens.

oid were not detected despite repeated immunization. In contrast, isohemagglutinins were constantly detected (titer: 32$128 \times 10^{-1}$ ) and serum IgG, IgA, IgM, and IgE levels were normal or above age-matched values (Table I). No monoclonal Ig components were present. A search for restricted heterogeneity of T-cell receptor rearrangements of the $\beta$ and $\gamma$ chain was negative (not shown). No immunological abnormalities were found in the parents or sisters.

Genetic studies. Because an X-linked inheritance was strongly suspected on the basis of the familial pedigree, $X$ chromosome inactivation of leukocytes from possible carriers was

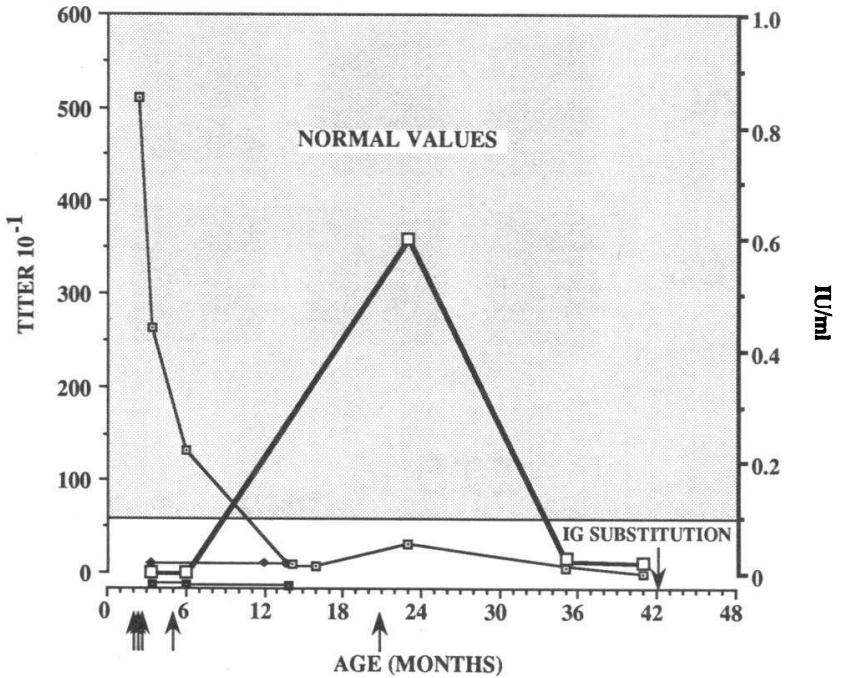

Figure 3. Time course of serum antibody responses. (ーロ $\rightarrow$ ) Tetanus toxoid (IU/ml) (ELISA); (-๑一) polio virus (titer $\left.\times 10^{-1}\right)$ (seroneutralization); (- -) Bordetella pertusis (titer $\left.\times 10^{-1}\right)$ (agglutination); (一-) diphtheria toxoid (IU/ml) (ELISA). Arrows represent immunization shots with tetanus and diphtheria toxoids, poliovirus, and Bordetella pertusis. 
performed. It has previously been shown that obligate carriers of three X-linked ID (XL SCID, XLA, and WAS) exhibit a nonrandom pattern of inactivation in some or all leukocyte subsets (19-23). The $X$ chromosome inactivation study was based on the differential methylation of the inactivated $X$ chromosome by using RFLP markers, the pSPT 19-1 probe from the PGK locus and the hypervariable locus DXS255. These probes detect RFLP after double digestion of human genomic DNA with the enzymes BstXI and PstI. The use of the methylation-sensitive enzyme HpaII discriminates the inactivated allele (16). Among the five female subjects studied (I1, II5, III4, 5,7 in Fig. 4) a polymorphism was detected with pSTP19.1 in four. The mother of the propositus (II5) was informative with the DXS255 marker. The validation of the use of the DSX255 marker in $\mathrm{X}$ inactivation studies was previously performed by the study of $X$ inactivation pattern in 47 females. They displayed identical $X$ inactivation pattern with this probe compared to the pSTP19.1 probe specific for the PGK gene. For the
PGK gene, the unmethylated fragment studied is associated with the active $\mathrm{X}$ chromosome; in contrast, methylation of the corresponding M27 $\beta$ sequence is associated with the active $X$ chromosome (18). Furthermore, although the methylation and nonmethylation pattern of the $5^{\prime}$ region of the PGK gene always fully correlates with the inactive and active $X$ chromosome, respectively, only the methylation of the $M 27 \beta$ sequence fully correlates with activation, whereas the inactive allele is often partially methylated (24). This did not affect the interpretation as long as only the status of the unmethylated allele is considered. Thus, a random pattern of $\mathrm{X}$ inactivation detected by the M27 $\beta$ probe is characterized by four bands after HpalI digestion, although only two or three bands are detected in a nonrandom pattern with a complete absence of the fourth band. As shown in Fig. $4 A$, the patient's sister III5 exhibited a random pattern of $\mathrm{X}$ inactivation in $\mathrm{E}(+), \mathrm{PMN}$, and $\mathrm{EBV} \mathrm{B}$ cells. In contrast, her sister III7 (Fig. $4 A$ ) and mother II5 (Fig. 4 B) presented nonrandom inactivation of the $\mathrm{X}$ chromosome in
I

II

III

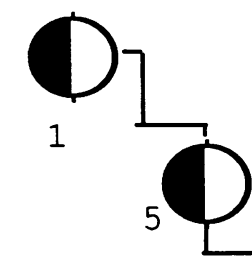

4

Hpall

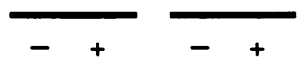

PMN

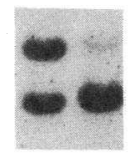

T IYM
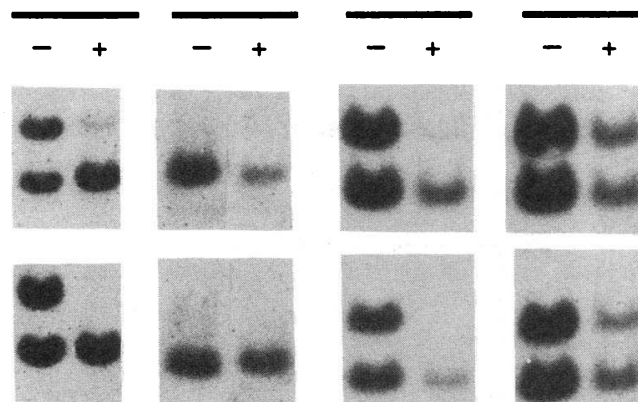

$-+$
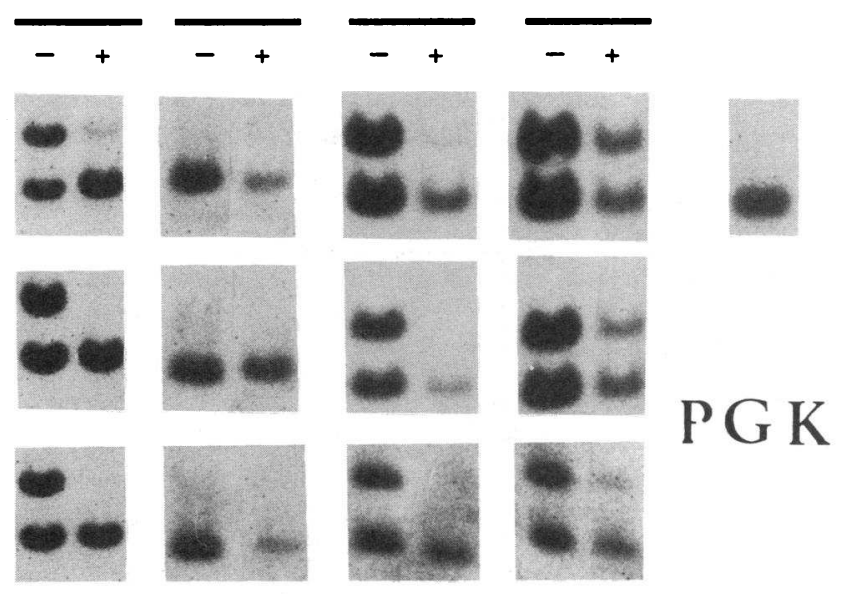

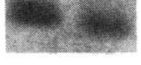

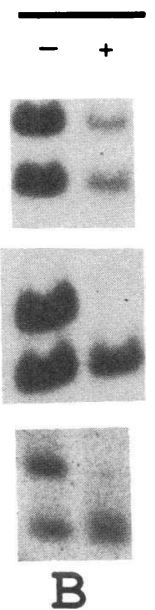

\section{II5}

\section{PMN T IYM EBV CL}

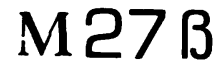

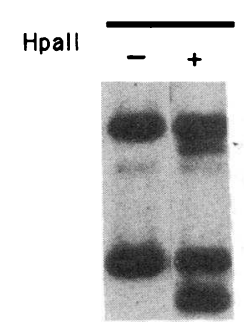
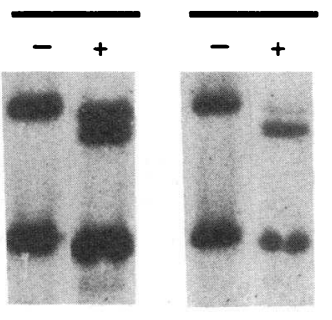

Figure 4. (A) Study of the X chromosome inactivation pattern of five female members of the family. The study was performed on DNA isolated from PMN, T, or EBV B cells; digested with (Pst l + BstXI) \pm HpaII; and hybridized with the PGK probe. Densitometric analysis was performed on the remaining upper and lower bands, respectively, after Hpall addition in the study of grandmother I1-PMN, 7.4, 157; $\mathrm{E}^{+}, 0.0,167$; EBV cell lines, 1.5, 139; In the study of the sister III4 -PMN, 6.5, 192; $\mathrm{E}^{+}, 0.0,34$; EBV cell lines, 0.6, 87; and the study of the sister III7-EBV cell lines; 1.9 , 46. (B) $X$ chromosome inactivation study of the mother (II5) was extended by reprobing the same Southern blot as in $A$ with the hypervariable marker DXS255. 
T lymphocytes and EBV cell line but random inactivation in PMN. The two other female subjects, the sister III7 and the grandmother I1 (Fig. $4 A$ ) show marked skewing in all cells subsets. Such extreme lyonization can be observed in a low percentage of normal female (22) probably dependent on the number of cells present at the time of $X$ inactivation. A thin upper band can, however, be observed in the PMN subset of these two subjects after HpalI addition; this band is absent in the $\mathrm{T}$ cell population. Densitometric analysis (Fig. $4 \mathrm{~A}$ ) indicates that the same $\mathrm{X}$ is always active in $100 \%$ of the $\mathrm{T}$ cells, and in at least $95 \%$ of the PMN, the other $\mathrm{X}$ being active in $0 \%$ of the T cells and 5\% of the PMN. This difference, which was observed twice in two different experiments, is however too small to draw definitively conclusions on the carrier status and on the affected cells in these two women. Nevertheless, it is interesting to note that in each of the four female subjects presenting a nonrandom pattern of $\mathrm{X}$ inactivation, the inactivated $\mathrm{X}$ chromosome is the same as the one transmitted to the propositus. As shown in Fig. $4 \mathrm{~A}$, although the 1.05-kb allele of PGK was undetectable in the $\mathrm{E}^{+}$cell populations of sister III7, a very thin band persisted in the $\mathrm{B}$ cells as shown by densitometric analysis (Fig. $4 \mathrm{~A}$ ). This suggests that the second $\mathrm{X}$ chromosome was not inactivated in all B cells.

The segregation of five polymorphic markers spanning the $\mathrm{X}$ chromosome was studied in the family. Their gene sequence was X-ter-DXS255-cent-DXS159-PGK-DXYS2X-DXS94 (25). It was possible to trace the two haplotypes defined in the grandmother (I1) into her progeny. Interestingly, the haplotype expressed by the patient was also detected in his two sisters who exhibited a nonrandom $\mathrm{X}$ chromosome inactivation pattern. In each of the four female subjects concerned, the inactivated $\mathrm{X}$ chromosome was the same as the one transmitted to the propositus (Fig. 4). Conversely, the second haplotype was found in the unaffected maternal uncle of the propositus (II7). In the patient's sister III5, a recombination was detected between DXS159 and DXYS2X. Since the pattern of the X chromosome inactivation was random in this subject, it indicates that the disease locus most probably resides proximal to the region DXYS2X.

\section{Discussion}

The patient studied in this work presents evidence for a persisting $\mathrm{T}$ and $\mathrm{B}$ cell immunodeficiency characterized by low and declining antigen-specific responses in vivo and in vitro. This was associated with progressively intractable diarrhea. Given the family history and the absence of evidence for an acquired immunodeficiency, it seems probable that this child was suffering from an inherited immune defect.

The fact that two brothers and at least one maternal uncle were similarly affected pointed to a recessive $\mathrm{XL}$ inheritance. This was confirmed by the lack of any immune deficiency in the female members of the family and by the nonrandom $\mathrm{X}$ inactivation pattern found in the grandmother, the mother and two of the three sisters. The patient presented none of the characteristics of the known $\mathrm{X}$ immunodeficiencies. Indeed, a normal NBT test result ruled out $\operatorname{CGD}(26,27)$, and the presence of polyclonal hypergammaglobulinemia was inconsistent with XLA and the hyper-IgM syndrome $(28,29)$. The clinical and immunological presentation was also inconsistent with XL lymphoproliferative syndrome (6), in that clinical manifestations appeared very early in life and were not those encoun- tered in XL lymphoproliferative syndrome (aplastic anemia, lymphoma, hepatitis, or hypogammaglobulinemia). In addition, no serum antibody to EBV could be detected in the patient and EBV was not found in blood mononuclear cells by Southern blot hybridization. WAS was unlikely because there were no quantitative or qualitative platelet abnormalities, no history of eczema and normal IgM levels. In addition, the X inactivation pattern in the carriers did not correspond to that observed in WAS carriers, i.e., nonrandom $\mathrm{X}$ inactivation in all leukocytes $(22,23)$. Finally, XL SCID, characterized by low T-cell counts and normal or increased B-cell counts (30), did not fit this case because of the presence of a normal number of $T$ cells (except during the first 4 mo of life) that were partially functional and were not of maternal origin. We therefore hypothesized the occurrence of a previously undescribed Xlinked immunodeficiency in this family. This syndrome is characterized by functional defects of both $\mathrm{T}$ and $\mathrm{B}$ cells, the molecular origin of which is unknown. The obligate carrier's mother exhibits a nonrandom $\mathrm{X}$ inactivation in $\mathrm{T}$ and $\mathrm{B}$ lymphocytes, as in XL SCID carriers $(19,20)$, indicating that the gene product of the disease locus is necessary for the normal development of T and B cells (31). Taking into account the results of the inactivation studies for the determination of the carrier status of the sisters, RFLP analysis indicated that the gene locus probably maps above DXYS2X (given the recombination found in sister III5).

Two types of molecular defect could account for this immunodeficiency. First, it might result from the mutation of an unknown and new XL gene involved in T/B lymphocyte differentiation and function. Secondly, and more probably, it might be the consequence of a different mutation of the XL SCID locus. This latter hypothesis is based on the T- and B-cell dysfunctions observed, together with an $\mathrm{X}$ inactivation pattern in the carriers identical to that in XL SCID carriers $(19,20)$. In addition, RFLP findings were consistent with a mutation in the proximal Xq region near PGK similar to that in XL-SCID (4), but did not rule out a locus on the short arm. Interestingly, another XL combined immunodeficiency has been recently described, in one family over three generations (32). However, in this family, patients survived postinfancy or even into adulthood. This suggests a less severe form of immunodeficiency. These patients also displayed normal concentration of immunoglobulines except for an elevated IgE, poorly functional $\mathrm{T}$ cells, and absence of diphtheria toxoid antibody response contrasting with a rise in Candida albicans antibody (32). It would thus be interesting to know the results of RFLP study in this pedigree.

There have been other examples of immune defects thought to be attenuated XL forms. Indeed, some XLA patients have $B$ cells with residual immunoglobulin production; no evidence for another locus was detected in segregation studies (33). In addition, XL thrombocytopenia might be an attenuated form of WAS, inasmuch as the encoding gene maps to the same region as that of WAS (34).

Further characterization of the molecular defect responsible for the novel XL immunodeficiency that we describe may contribute to our understanding of the role of XL genes in T/B cell differentiation and function.

\section{Acknowledgments}

We are grateful to Ms. O. Journet, M. Dousseau, C. Harré, C. Jacques, and M. C. Pelletreau for expert technical assistance and to Ms. D. 
Bresson for typing the manuscript. We wish to thank Drs. M. P. Lefranc and T. W. Mak for the generous gift of $\beta$ and $\gamma$ TCR probes and Drs. I. Craig, P. Szabo, P. L. Pearson, J. Singer-Sam, and J. Weissenbach for the generous gift of $\mathrm{X}$ polymorphic markers.

This work was supported by INSERM and Caisse Nationale d'Assurances Maladie des Travailleurs Salariés.

\section{References}

1. Teahan, C., P. Rowe, P. Parker, N. Totty, and A. W. Segal. 1987. The $X$-linked chronic granulomatous disease gene codes for the $\beta$-chain of cytochrome b-245. Nature (Lond.). 327:720-728.

2. Dinauer, M. C., S. H. Orkin, R. Brown, A. J. Jesaitis, and C. A. Parkos. 1987. The glycoprotein encoded by the X-linked chronic granulomatous disease locus is a component of the neutrophil cytochrome b complex. Nature (Lond.). 327:717-720.

3. Malcolm, S., G. de Saint Basile, B. Arveiler, Y. L. Lau, P. Szabo, A. Fischer M. Debré, R. E. Callard, M. E. Robertson, J. A. Goodship, et al. 1987. Linkage of random DNA fragments from Xq21.3-22 to X-linked agammaglobulinemia. Hum. Genet. 77:172-174.

4. De Saint-Basile, G., B. Arveiler, I. Oberlé, S. Malcolm, M. Debré, R. Levinsky, A. Fischer, C. Griscelli, and J. L. Mandel. 1987. Close linkage of the locus for $\mathrm{X}$ chromosome-linked severe combined immunodeficiency to polymorphic DNA markers in Xq11-q13. Proc. Natl. Acad. Sci. USA. 84:7576-7579.

5. Mensink, E. J. B. M., A. Thompson, L. Sandkuyl, M. Kraakman, J. Schot, T. Espanol, and K. Schuurman. 1987. X-linked immunodeficiency with hyperimmunoglobulinemia M appears to be linked to the DXS42 restriction fragment length polymorphism locus. Hum. Genet. 76:96-99.

6. Skare, J. C., A. Milunsky, K. S. Byron and J. L. Sullivan. 1987. Mapping the X-linked lymphoproliferative syndrome. Proc. Natl. Acad. Sci. USA. 84:20152018.

7. Peacocke, M., and K. A. Siminovitch. 1987. Linkage of the Wiskott-Aldrich syndrome with polymorphic DNA sequences from the human $\mathrm{X}$ chromosome. Proc. Natl. Acad. Sci. USA. 84:3430-3433.

8. De Saint-Basile, G., B. Arveiler, N. J. Fraser, Y. Boyd, I. W. Craig, C. Griscelli, and A. Fischer. 1989. Close linkage of hypervariable marker DXS255 to disease locus of Wiskott-Aldrich syndrome. Lancet. 2:1319-1320.

9. Fischer, A., F. Le Deist, A. Durandy, and C. Griscelli. 1985. Separation of a population of human $\mathrm{T}$ lymphocytes that bind prostaglandin E2 and exert a suppressor activity. J. Immunol. 134:815-819.

10. Brottier, P., L. Boumsell, C. Gelin, and A. Bernard. 1985. T-cell activation via $\mathrm{CD} 2$ (T, gp 150) molecules: accessory cells are required to trigger T-cell activation via CD2 D66 plus CD2 9-6/TII-1 epitopes. J. Immunol. 135:1624-1632.

11. Ochs, H. D., S. D. Davis, and E. Mickelson. 1974. Combined immunodeficiency and reticuloendotheliosis with eosinophilia. J. Pediatr. 35:463-465.

12. Tosato, G., S. E. Pike, L. R. Koshi, and R. M. Blaese. 1982. Selective inhibition of inhibitory cell functions by cyclosporin A. J. Immunol. 128:19861991.

13. Old, J. M. 1986. Fetal analysis. In Human genetic Diseases, a Practical Approach. K. E. Davies, editor. IRL Press, Oxford, UK. 1-17.

14. Yanagi, Y., A. Chan, B. Chin, M. D. Minden, and T. W. Mak. 1985. Analysis of cDNA clones specific for human T cells and the $\beta$ chains of the $T$ cell receptor heterodimer from human T cell line. Proc. Natl. Acad. Sci. USA. 82:3430-3434

15. Lefranc, M. P., and T. H. Rabbitts. 1985. Two tandenly organized human genes encoding the T-cell constant-region sequences show multiple rearrangement in different T-cells types. Nature (Lond.). 316:463.

16. Arveiler, B., G. de Saint Basile, A. Fischer, C. Griscelli, and J. L. Mandel.
1990. Germ-line mosaicism simulates genetic heterogeneity in Wiskott-Aldrich syndrome. Am. J. Hum. Genet. 46:906-911.

17. Keith, D. H., J. Singer-Sam, and A. D. Riggs. 1986. Active X chromosome DNA is unmethylated at eight CCGG sites clustered in a guanosine-plus-cytosine-rich island at the $5^{\prime}$ end of the gene for phosphoglycerate kinase. Mol. Cell. Biol. 6:4122-4125.

18. Boyd, Y., and N. J. Fraser. 1990. Methylation patterns at the hypervariable X-chromosome locus DXS255 (M27 $\beta$ ): correlation with X-inactivation status. Genomics. 7:182-187.

19. Puck, J. M., R. L. Nussbaum, and M. E. Conley. 1987. Carrier detection in X-linked severe combined immunodeficiency based on patterns of X chromosome inactivation. J. Clin. Invest. 79:1395-1400.

20. Conley, M. E., A. Lavoie, C. Briggs, P. Brown, C. Guerra, and J. M. Puck. 1988. Nonrandom X chromosome inactivation in B cells from carrier X chromosome-linked severe combined immunodeficiency. Proc. Natl. Acad. Sci. USA. 85:3090-3094.

21. Fearon, E. R., J. A. Winkelstein, C. I. Civin, D. M. Pardoll, and B. Vogelstein. 1987. Carrier detection in X-linked agammaglobulinemia by analysis of X-chromosome inactivation. N. Engl. J. Med. 316:427-431.

22. Fearon, E. R., D. B. Kohn, J. A. Winkelstein, B. Vogelstein, and R. M. Blaese. 1988. Carrier detection in the Wiskott-Aldrich syndrome. Blood. 72:1735-1739.

23. Greer, W. L., P. C. Kwong, M. Peacocke, P. Ip, L. A. Rubin, and K. A. Siminovitch. 1989. X-chromosome inactivation in the Wiskott-Aldrich syndrome: a marker for detection of the carrier state and identification of cell lineages expressing the gene defect. Genomics. 4:60-67.

24. Hendriks, R. W., M. De Vries, R. G. J. Mensink, M. E. M. Kraakman, I. F. A. M. Mollee-Versteegde, A. J. P. Veerman, L. A. Sandkuyl, and R. K. B. Schuurman. 1991. Diagnosis of Wiskott-Aldrich syndrome by analysis of the $\mathrm{X}$-chromosome inactivation patterns in maternal leucocyte populations using the hypervariable DXS255 locus. Clin. Exp. Immunol. 84:219-222.

25. Mandel, J. L., H. F. Willard, R. L. Nussbaum, G. Romeo, J. M. Puck, and K. E. Davies. 1989. Report of the committee on the genetic constitution of the $X$ chromosome. Cytogenet. Cell. Genet. 51:384-437.

26. Segal, A. W. 1987. Absence of both cytochrome b245 subunits from neutrophils in X-linked chronic granulomatous disease. Nature (Lond.). 326:88-91.

27. Parkos, C. A., R. A. Allen, C. G. Cochrane, and A. J. Jesaitis. 1987. Purified cytochrome $\mathrm{b}$ from human granulocyte plasma membrane is comprised of two polypeptides with relative molecular weights of 91,000 and 22,000. J. Clin. Invest. 80:732-742.

28. Bruton, O. C. 1952. Agammaglobulinemia. Pediatrics. 9:722-728.

29. Rosen, F. S., S. V. Kevy, E. Merler, C. A. Janeway, and D. Gitlin. 1961. Recurrent bacterial infections and dysgammaglobulinemia: deficiency of $7 \mathrm{~S}$ gammaglobulins in the presence of elevated 19S gammaglobulins. Pediatrics. 28:182195.

30. Griscelli, C., A. Durandy, J. L. Virelizier, J. J. Ballet, and F. Daguillard. 1978. Selective defect of precursor $T$ cells associated with apparently normal B lymphocytes in severe combined immunodeficiency disease. J. Pediatr. 93:404411.

31. Lyon, M. F. 1972. X chromosome inactivation and developmental patterns in mammals. Biol. Rev. 47:1-35.

32. Brooks, E. G., F. C. Schmalstieg, D. P. Wirt, H. M. Rosenblatt, L. T. Adkins, D. P. Lookingbill, H. E. Rudloff, R. A. Rakusan, and A. S. Goldman. 1990. A novel X-linked combined immunodeficiency disease. J. Clin. Invest. 86:1623-1631.

33. Kwan, S. P., J. Terwilliger, R. Parmley, G. Raghu, L. A. Sankuyl, J. Ott, H. Ochs, R. Wedgwood, and F. Rosen. 1990. Identification of a closely linked DNA marker, DXS178, to further refine the X-linked agammaglobulinemia locus. Genomics. 6:238-242.

34. Donner, M., M. Schwartz, K. U. Carlsson, and L. Holmberg. 1988. Hereditary X-linked thrombocytopenia map to the same chromosomal region as the Wiskott-Aldrich syndrome. Blood. 72:1849-1853. 